DOI 10.37882/2223-2982.2021.04.37

\title{
ИСПОЛЬЗОВАНИЕ ДВИГАТЕЛЬНО-ЭМОЦИОНАЛЬНЫХ ИГР В ПРОЦЕССЕ ПРЕДМЕТНО-ПРАКТИЧЕСКОЙ ДЕЯТЕЛЬНОСТИ ДОШКОЛЬНИКОВ С ТМНР
}

\section{THE USE OF MOTOR AND EMOTIONAL GAMES IN THE PROCESS OF SUBJECT- PRACTICAL ACTIVITIES OF PRESCHOOL CHILDREN WITH TMNR}

\section{O. Shokhova}

Summary: The article presents the experience of organizing psychological and pedagogical work in combined preschool departments of GBOU schools, for preschool children with severe multiple developmental disorders, and the implementation of pedagogical technology for the formation of emotional response in the work based on the activation of the motor sphere. The problem is formulated: the need to find and develop methods of psychological and pedagogical assistance to preschoolers with TMNR, which use motor tasks that "work" to identify and overcome difficulties in the development of communication, arbitrariness, emotional sphere, etc. The article presents the results and analysis study the state of emotional response in children, study categories at the level of motor development, this description of the quality of their emotional reactions in a static position and when changing postures in the process of mobilization, the educational methodology on the development of motor component of emotional response. These correctional and developmental classes can be organized in a special and inclusive educational environment. The results showed the effectiveness of these techniques in the development and correction of children with MSDD emotional-personal sphere and behavior, but these studies do not cover the entire range of psycho-pedagogical problems encountered in preschool children with Sens and this article allows to outline the range of problems for future research.

Keywords: emotional-volitional sphere, emotional response, preschoolers with severe multiple developmental disorders, complex multiple developmental disorders, motor sphere, static poses, changing body posture in a mobile state, emotional-motor games, expressive movements.

\author{
Шохова Ольга Валентиновна \\ К.п.н., дочент, ГОУ ВО Московской области «Московский \\ государственный областной университет» г. Москва \\ fakul-spip@mgou.ru
}

Аннотация: В статье представлен опыт организации психолого-педагогической работы в комбинированных дошкольных отделениях ГБОУ школах, детям дошкольного возраста, имеющих тяжелые множественные нарушения развития (ТМHР), и реализация педагогической технологии формирования эмоционального реагирования применения в работе, основанных на активизации двигательной сферы. Сформулирована проблема: необходимость поиска и разработки методов психолого-педагогической помощи дошкольникам с ТМНР, при которых используются двигательные задания, «работающие» на выявление и преодоление трудностей в развитии общения, произвольности, эмоциональной сферы и т.п. В статье приведены результаты и анализ изучения состояния эмоционального реагирования у детей изучаемой категории на уровне двигательного развития, даны описания качества их эмоциональных реакций в статическом положении и при изменении позы в процессе мобилизации, представлена обучающая методика по развитию двигательного компонента эмоционального реагирования. Данные коррекционно-развивающие занятия можно организовывать в условиях специальной и инклюзивной образовательной среды. Результаты исследований показали эффективность этих методик в развитии и коррекции у дошкольников с ТМНР эмоционально-личностной сферы и поведения, однако эти исследования не охватывают всего круга психолого-педагогических проблем, встречающихся у дошкольников с 00П и данная статья позволяет наметить круг проблем будущих исследований.

Ключевые слова: эмоционально-волевая сфера, эмоциональное реагирование, дошкольники с тяжелыми множественными нарушениями развития, комплексные множественные нарушения развития, двигательная сфера, статические позы, изменение позы тела в мобильном состоянии, эмоционально-двигательные игры, выразительные движения.
Д вигательное развитие человеческого организма обладает своей структурой, своим собственным невербальным языком и законами проявлений. тия оно «продвигается» через базовые схемы движений в том темпе и по тем законам, которые заложены Природой. Каждый динамический или позовый рефлекс, каждая схема движений, система их координаций появляются в определенное время. Этим временем и является тот период, в котором базовые движения усваиваются, отрабатываются, исследуются и объединяются в целостные системы функционирования тела. Закрепленные схемы становятся основой для формирования последующих более сложных систем. Таким образом. создается база для эффективного перехода человека на следующий этап двигательного развития, что предполагает тесную интеграцию с общим психическим развитием. Она ярко проявляет себя в ранний и дошкольный периоды. Многие психологи и педагоги отстаивали позицию, что интеллектуальное развитие ребенка зависит от двигательного (Н.А. Бернштейн, Л.С. Выготский, М. Ибука, П.Ф. Лесгафт, М. Монтессори, Ж. Пиаже, Сперри Р., Ханнафорд К. и др.) 
$[1,3,8,9]$. Чем активнее на возрастном этапе реализуется потребность ребенка в разнообразных движениях, тем эффективнее и продуктивнее у кого развивается психическая и речевая деятельности, мыслительные процессы, механизмы воображения и разных видов творчества. Движение, связанное с работой мышечного аппарата, обеспечивает эффективную работу мозга и активную жизнь. Личность и физическое состояние ребенка формируются в движениях, он ищет возможности подвигаться, проявляя эмоциональную реакцию на любую новизну, у него возникает чувство любопытства, в результате чего складывается такое важное качество как интерес, основополагающая познавательная эмоциональная реакция, которая ложится в основу осознания окружающего мира. Именно она побуждает ребенка к освоению мира и его расширению в различных пространственных измерениях. При этом движения превращаются в источник радостного и непосредственного познания, детализирует, продвигают понимание окружающего мира и позволяют закреплять приобретаемый опыт.

Двигательное развитие предполагает:

- становление рефлекторных младенческих движений и их взаимосвязанность;

- интеграцию безусловных и условных рефлексов (динамических (мобильных) и позовых) с осуществлением их сознательного контроля;

- развитие целостных схем движений тела (переворотов с живота на спину и, наоборот; умения сидеть или стоять и пр.) и формирование переходных моментов (основных схем движений, обеспечивающих появление умения переворачиваться или садиться и пр.);

- становление разнообразных систем координации движений (совместных ручных движений, слухозрительно-моторной координаций, совместных с сопровождающим крупных и мелких движений);

- обретение возможности латеральности (взаимодействия левой и правой сторон, левого и правого полушарий головного мозга), центрации тела (взаимодействия верха и низа, неокортекса, среднего мозга), чувства фокусирования на собственном теле;

- создание системы контроля движений (положения тела во время произвольной деятельности);

- овладение темпом и ритмом движений;

- ощущение позы и формы тела;

- развитие телесного кинестетического интеллекта (моторного аспекта сознания, поведения и деятельности);

- образование связей между схемами движений, эмоциональными, познавательными психическими процессами и поведением [1, 2, 3, 5].

Дети с тяжелыми множественными нарушениями развития (ТМHР) пребывают в «обездвиженной» жизненной среде, что приводит к статическому накоплению знаний или вынужденной стагнации и торможению в его психо-физическом развитии. Центральным вопросом в их двигательном развитии является вопрос о том, насколько плавно, сообразно личностному состоянии и природе ребенка проводятся попытки и способы привести его к осознанным движениям. Важно понимать, что осознанные движения ведут и к контролируемому поведению. В исследовании двигательного компонента эмоционального реагирования у дошкольников с ТМНР, мы обратили внимание на то что, если у ребенка отсутствует двигательный контроль за собственным телом, у него активнее проявляются негативные эмоции, которые бывают долговременными, неуправляемыми, очень истощают ребенка и сопровождаются появлением беспорядочных движений, усилением патологических поз и рефлексов $[2,4,7]$.

Формирование произвольных движений и двигательного контроля происходит в направлении от центра тела к конечностям, от головы к копчиковому отделу позвоночника, от верхних конечностей к нижним. Знание подобных свойств этого процесса может помочь правильно организовать двигательное развитие ребенка. Важно стимулировать и активизировать его базовые истоки - возникновение адекватных динамических и позовых рефлексов и их интеграцию в общую двигательную систему организма. Необходимо учитывать, что каждая такая схема основывается на базовых рефлексах, соотносится с другими схемами движений, поддерживает функционирование головного мозга. Несформированность основных движений приводит к задержке становления произвольности психо-физических и речевых процессов, поведенческим и учебным нарушениям.

Выполнение правильных и точных движений неразрывно связана с овладением навыками и умениями, такими как сгибание и разгибание, удлинение и сокращение, сжатие и отталкивание, дотягивание и притягивание, которые складываются в последовательную координацию двигательных актов. Эти взаимосвязи позволяют ребенку выбирать правильные действия при реагировании на стимулы окружающего мира (Эриксон К.Э. 1988) $[1,5]$. Двигательное развитие отражается на структуре, качестве и уровне осознания, на ритме и темпе движений, на кинестетическом восприятии и сопровождается положительными эмоциями, которые возникают благодаря усвоению новых действий. Нейрофизиолог К. Ханнафорд [8] в исследованиях, посвященных взаимозависимости двигательного и интеллектуального развития, подчеркивает, что движение является составной частью процесса научения. Оно пробуждает, реализует и активирует эмоции, умственные способности и личностное «Я». Оно встраивает, закрепляет новый опыт и информацию на нейрофизиологическом уровне. Русский ученый П.Ф. Лесгафт $[2,3,4]$ указывал на приоритетность двигательного развития и подчеркивал значение содержания физического образования (упражнений и игр) как метода 
познания. При классификации физических упражнений он выделил по четыре основные группы: простые упражнения в виде движений головы, туловища, конечностей и сложные упражнения с разновидностями движений и метаний; упражнения с увеличивающимся напряжением при двигательных действиях с палками и гирями, при метании деревянных и железных шаров, прыжках, лазании, борьбе и удержании равновесия; упражнения, предусматривающие ознакомление с пространственными и временными отношениями при ходьбе в заданном темпе, прыжках на определенное расстояние и метании в цель; систематизированные упражнения в процессе простых и сложных игр.

Дети с ТМНР не в состоянии непосредственно приобретать необходимый опыт движений, что ведет к пассивности в психической, познавательной, речевой и предметно-практической деятельности. У них резко ограничены возможности овладения знаниями и их использования, они быстро утомляются, склонны к истощению внимания. У таких детей отсутствуют осознанные двигательные ощущения окружающего мира, многие естественные эмоциональные реакции, они не владеют способами познания окружающего пространства действования в нем и выбором различных реакций на поступающие сенсомоторные стимулы. Фактор депривации, начиная с овладения движениями головы, значительно тормозит включение органов чувств в процессы восприятия. Зрительная депривация, при наличии частичной атрофии зрительного нерва, вызывающая слабовидение, препятствует формированию образов предметов и явлений, видимых на дальнем или близком расстоянии, в трехмерном масштабе, приводит к ограничениям периферического зрения и трудностям фокусирования взгляда на мелких предметах и деталях. Тактильно-двигательная депривация возникает у них из-за поражения нервной иннервации рук и невозможности регулировать мышечный статус, снижая при этом кинестетическое восприятие и обуславливая сложности прикосновения к предметам и манипулирования ими. Телесная (физическая) депривация является следствием, того, что дети не могут самостоятельно принимать разные положения тела, избегать дискомфорта в неудобных позах и обретать комфортное удобное положение, что необходимо для формирования образа собственного тела, осознания его границ, для самосохранения и реализации новых двигательных актов. Эмоциональная и социальная депривации происходит в результате того, что ребенок не способен сфокусировать взгляд и внимание на лице взрослого, продолжительно и эффективно с ним взаимодействовать, в том числе подражая его эмоциональным реакциям $[2,3,4,7]$.

Описанные процессы, тесно связанны с характером изучаемых явлений и обосновывают выбор цели, задач и направлений разработанной нами педагогической технологии по развитию двигательного компонента эмоци- онального реагирования у детей с ТМНР.

Цель обучения состояла в формировании и развитии двигательного компонента эмоционального реагирования у детей с ТМНР в результате мобилизации и совершенствовании его возможностей в процессе специально организованной игровой деятельности; в создании условий для пробуждения у детей стремления к максимальному раскрытию собственного двигательного потенциала в процессе обучения. При реализации педагогической технологии мы ставили следующие задачи:

1. стимулирования двигательной, эмоциональной, психической и речевой активности ребенка и развития общей и мелкой моторики, зрительно-моторной координации;

2. активизации произвольности двигательного компонента эмоционального реагирования на эмоционально-личностном и ситуативно-личностном уровнях общения и взаимодействия со взрослым;

3. формирования эмоциональных реакций в виде невербальных средств коммуникации (жестов, мимики); обучение способам выражения себя вовне, проявления способности к творчеству в свободном эмоциональном переживании, развития эмоционально-двигательной регуляции;

4. обучения детей пониманию и воспроизведению эмоциональных состояний на двигательном уровне и овладению способностью действовать по подражанию, по образцам действий взрослого или сверстников;

5. достижения значимых эмоционально-личностного и личностно-ситуативного уровней взаимодействия с партнерами по общению;

6. освоения детьми с ТМНР предметно-практической деятельности и самостоятельной реализации эмоциональных состояний в играх-драматизациях с партнерами по общению и др.

Организационная структура коррекционно-развивающих занятий по формированию у детей двигательного компонента эмоционального реагирования в специально организованной игровой деятельности имела определенную последовательность $[4,6,7]$ :

1. Стимуляция двигательной и эмоциональной сферы у детей с ТМНР с использованием приемов спонтанного и целенаправленного «заражения».

2. Формирование у них представлений об эмоциональных проявлениях при восприятии действий и реакций соучастников в практической деятельности, подражания их двигательным эмоциональным действиям на наглядной, так и на вербальной основах.

3. Выполнение упражнений с различными видами помощи детям либо более обширный, либо частичной - в совместной деятельности, в действиях по подражанию, по зрительному образцу и по словесному описанию; 
4. Уточнение и осознание эмоциональных проявлений реакций (в движениях, в процессе ознакомления с окружающим пространством, при коммуникации) в специально организованных ситуациях и в непосредственной деятельности.

Последовательность этапов проводимой обучающей работы представлена в схеме.

В реализуемых нами методах формирования у детей с ТМНР навыков двигательно-эмоциональной деятельности предусматривались следующие направления развития:

- общих движений и пространственной ориентировки в соответствии с онтогенетическим принципом: на уровне тела при изменении статической позы; в ограниченном (микро) пространстве при переходе к мобильной позе; в ограниченном (макро) пространстве при неупорядоченном изменении мобильной позы с перемещениями тела; при ритмичном построении и движениях по кругу;

- двигательно-эмоционального компонента: за контролем собственного тела, при мышечном напряжении и расслаблении, умения указывать на дискомфорт; способности к произвольному подражанию и выражению эмоциональных состояний; навыков передачи причинно-следственных связей при изменениях эмоциональных отношений;

- способов проявления готовности контактировать со взрослым и сверстниками, а также с окружающим пространством в процессе двигательно-коммуникативной деятельности; осознания собственного комфортного и дискомфортного состояний и способности оповещать об этом.

- эмоциональных проявлений и общения: готовности к общению; умения обращаться к партнеру с помощью невербальных средств, мимики и жестов; способности отражения эмоций заявленного персонажа игры или отношения, связанного с игровым сюжетом; понимания действий и реакций партнера по коммуникативному и игровому общению при диадном взаимодействии по принципу «ведущий - ведомый».

Специалист (педагог-дефектолог, специалист по ЛФК, а иногда и обученный родитель) оказывает ребенку с ТМНР помощь, которая сопровождается словесными комментариями, что превращает учебный процесс в активное общение, и в некоторой степени в соучастии. Содержание коррекционно-развивающего занятия формированию двигательного компонента эмоционального реагирования и порядок освоения предусмотренных действий показаны в схеме на рис 2.

Активизация двигательного компонента эмоцио- нального реагирования происходила на занятиях у специалиста-дефектолога, психолога, логопеда и раскрывалась в соответствии с тематическим планированием и учетом уровня развития каждого ребенка с ТМНР. Мобилизация у детей двигательной сферы становилась главной задачей на занятиях по физической культуре, на лечебной физкультуре и при массаже. В работе дефектолога, логопеда, психолога, музыкального сотрудника осуществлялась преемственность и взаимосвязь всех действий специалистов физического блока, что заключалась в освоении и закреплении навыков, полученных на профильных занятиях. Непосредственное участие специалистов по ФИЗО, ЛФК в занятиях, посвященных освоению окружающего пространства, развитию речи, способствовало созданию командного взаимодействия между специалистами. Во время такой работы между специалистами происходил обмен мнениями по формированию двигательных функций детей с целью достижения диагностического мониторинга и правильного нахождения комфортной позы доступных движений. Для каждого ребенка на занятии устанавливается индивидуальный двигательный режим, который детям позволяет пребывать не в неподвижном состоянии, а реализовывать свои двигательные возможности. Обучающее воздействие осуществляется в разных формах: при выполнении индивидуальных, диадных или групповых упражнений, в играх, предусматривающих различные степени подвижности, в систематических, плановых занятий совместных со здоровыми сверстниками, в инклюзивном режиме. Эмоционально-двигательные подвижные игры и упражнения под музыку, под песенки способствуют формированию у детей с ТМНР выразительности движений крупной и мелкой моторики, передаче эмоций в лицевом отражении. Главным в нашей работе мы считаем овладение, закрепление и автоматизацию эмоционально-двигательных навыков и физических качеств, достижение ритмичной гармоничности выполняемых детьми действий. Постоянная взаимосвязанная работа разных специалистов приводит к заметным положительным изменениям внешних и внутренних двигательно-эмоциональных возможностей детей с ТМНР (в практической, продуктивной, речевой деятельности), пробуждает у них готовность и стремление к позитивному, совместному взаимодействию со сверстниками, к проявлениям доступной самостоятельности.

Динамические наблюдения за участвующими в исследовании детьми послужили основанием для сопоставления и оценки возможностей обучаемости детей изучаемой категории. Данные, приведенные в рисунке 3, наглядно демонстрируют динамику развития двигательного компонента эмоционального реагирования в процессе обучения у детей всех уровней. В трех первых группах, несмотря на невысокие характеристики изучаемой функции в констатирующем эксперименте до начала обучения, в результате создания определенных условий - нахождения удобной позы при выполнении 


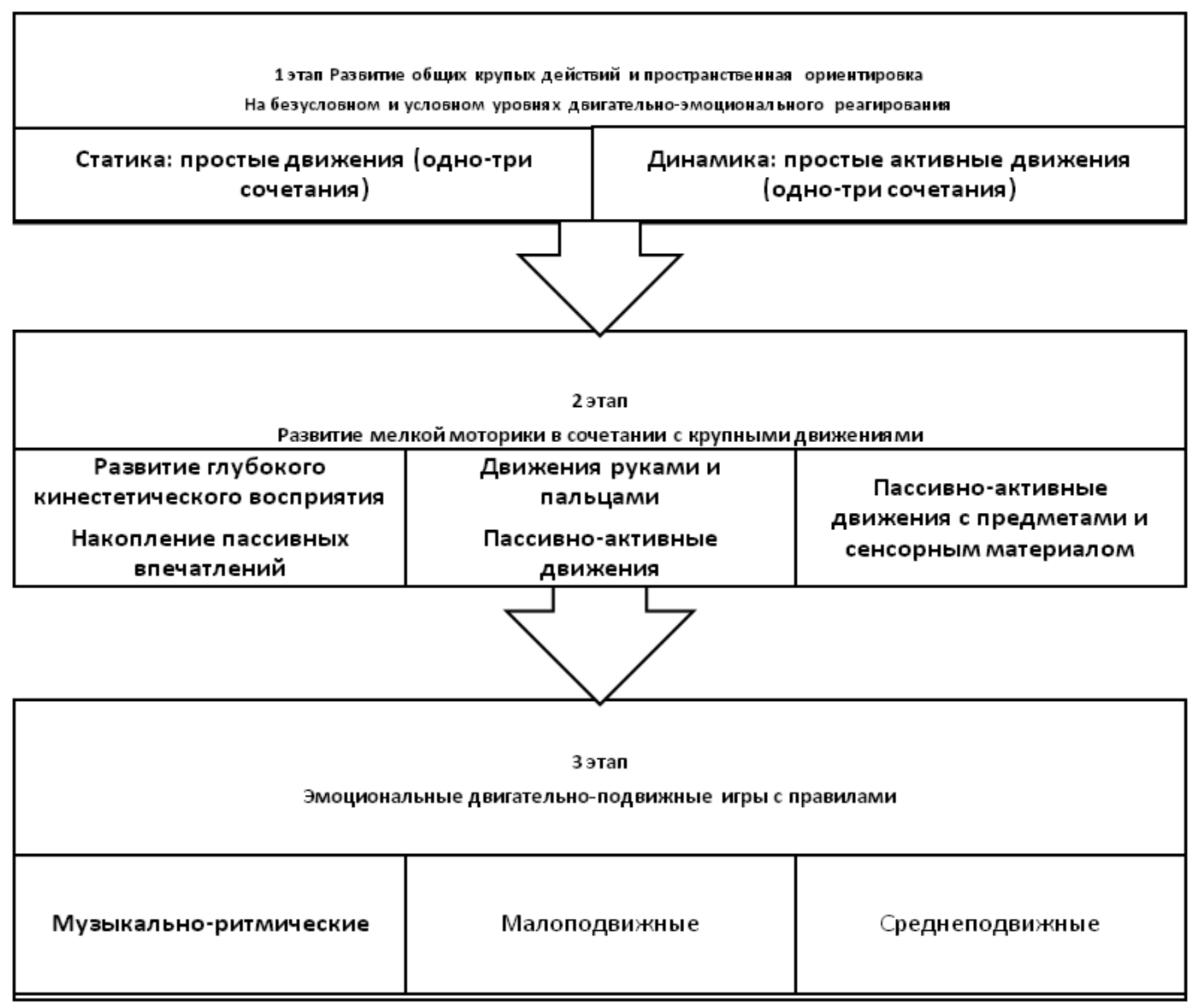

Рис. 1. Этапы коррекционно-развивающей работы по формированию двигательного компонента эмоционального реагирования у детей дошкольного возраста с ТМНР

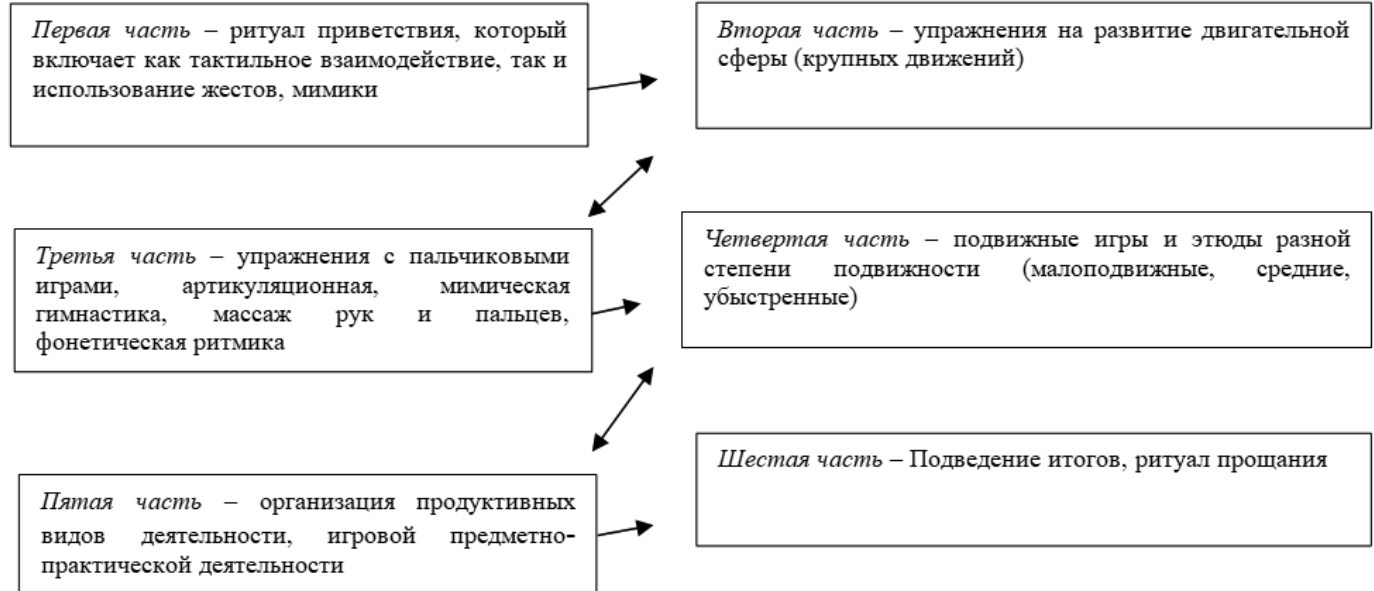

Рис. 2. Содержание коррекционно-развивающего занятия.

заданий, использования дополнительных приспособлений и т.п. - дети значимо повысили свои показатели. При выполнении двигательных заданий важно придерживаться определенной методики их проведения: чередовать активные движения с релаксацией; от простых движений, которыми они уже владеют, переходить к более сложным; в подвижных играх перемежать простые движения со сложными. Основные различия в показателях детей с ТМНР до обучения и после него заключались в следующем: снижении числа неадекватных проявлений эмоциональных реакций, преобладании более интенсивных и продолжительных положительных эмоций над отрицательными, расширении их репертуара в обращении с предметами и в способности действовать в различных коммуникативных ситуациях, что сказалось в интонационно окрашенных звукоподражаниях, отдельных словах и в простых фразах, произносимых как по образцам, даваемым взрослым, так и самостоятельно. У детей 


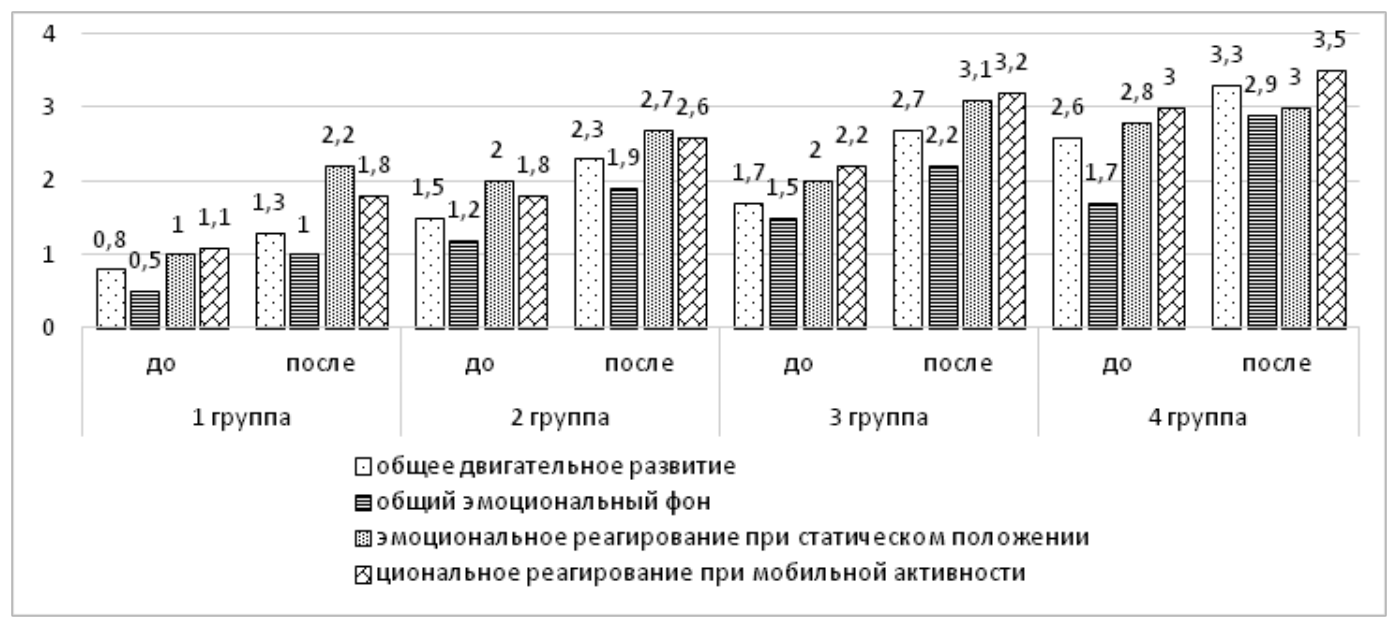

Рис. 3. Динамика развития двигательного компонента эмоционального реагирования после обучающего эксперимента у дошкольников с ТМНР.

первой (с очень низким уровнем развития ЭР) и второй (низкий уровень с динамикой развития ЭР) групп появился интерес к совершению целенаправленной деятельности, они стали быстрее вступать в контакт, обнаруживая при этом более продолжительный положительный эмоциональный настрой, длительное время смотрели в глаза взрослому, активнее подражали его эмоциональным выражениям и действиям; у них увеличилась продолжительность занятий. Их совместно-сопряженные со взрослым действия с предметами, выполняемые либо по подражанию, либо по образцу, теперь характеризовались некоторой легкостью и завершенностью. У детей третьей (средний уровень развития ЭР) и четвертой (выше среднего) групп активизация двигательного компонента способствовала расширению их возможностей; придавала большую уверенность их движениям; дети обнаруживали стремление активно передвигаться; игры вызывали у них удовольствие, взаимодействие со взрослым и сверстниками сопровождалось определенным эмоциональным подъемом. После обучения они начали ориентироваться на различные сенсорные характеристики объектов, стали проявлять к ним эмоциональное отношение, адекватное конкретной ситуации.

Таким образом, результаты обучения свидетельствуют о том, что психолого-педагогические особенности развития эмоционального реагирования у детей с ТМНР позволяют осуществлять диагностику общего уровня развития воспитанников изучаемой категории, с выраженными и с неосложненными нарушениями развития, но и способствуют качественному положительному изменению коррекционно-развивающей работы, учитывающей особое значение эмоционального реагирования и его влияния на все психо-физическое развитие детей с TMHP.

\section{ЛИТЕРАТУРА}

1. Горшкова Е.В. Методы эмоционально-двигательной психотехники для детей: развитие внутренней свободы и уверенности // Справочник педагога-психолога. Детский сад. 2016. № 5. С. 40-55.

2. Левченко И.Ю., Ткачева В.В., Приходько О.Г., Гусейнова А.А. Детский церебральный паралич. Дошкольный возраст [Текст] / И.Ю. Левченко, В.В. Ткачева, О.Г. Приходько, А.А. Гусейнова: Метод. пособие - М.: Образование Плюс; 2008. - 198 с.

3. Малюкова И.Б. Абилитация детей с церебральными параличами: формирование движений (театр исцеляющих движений») [Text]. - M.: Гном, - 2018. $110 \mathrm{c}$.

4. Симонова Т.Н. Система психолого-педагогической помощи детям дошкольного возраста с тяжелыми двигательными нарушениями [Текст]/ Т.Н. Симонова: Монография. - Астрахань, Астраханский университет, 2010. - 106 с.

5. Чернигина Е.В., Горшкова Е.В. Эффективность телесно-ориентированной психотехники в решении проблем психомоторного развития детей 4-5 лет с признаками СДВГ [Техt] // Психологическая наука и образование. - Изд-во, МГППУ. - 2008. - № 1.

6. Чистякова М.И. Психогимнастика. М.: Просвещение, 1990. 128 с.

7. Шохова 0.В. Экспериментальное исследование особенностей эмоционального реагирования у дошкольников с множественными нарушениями развития [Текст] /0.В. Шохова // Дефектология. - 2017. - № 3. - С. 31-41.

8. Hannaford C. «Smart moves» [Text] / C. Hannaford //Greate Ocean Publishers Arlington. - Virginia. - 2005.

9. Sperry R.W. The great cerebral commissure [Text] / R.W. Sperry // Scientific American. - 1964. - 210(1). - P. 42-52. 